\title{
Uzun Süreli Karın Ağrısı Şikayeti Olan Hastada Poliparazitizm Olgusu
}

\author{
Case of Polyparasitism with Long-Term Abdominal Pain in a Patient
}

\section{Nihal Doğan', Nazmiye Ülkü Koçman²}

'Eskişehir Osmangazi Üniversitesi Tıp Fakültesi, Tıbbi Mikrobiyoloji Anabilim Dalı, Parazitoloji Bilim Dalı, Eskişehir, Türkiye ²Eskişehir Osmangazi Üniversitesi Tıp Fakültesi, Tıbbi Mikrobiyoloji Anabilim Dalı, Eskişehir, Türkiye

\section{ÖZET}

Bağırsak protozoon ve helmintlerinin neden olduğu enfeksiyonların dünyada 3,5 milyar kişiyi etkilediği bilinmektedir. Uzun süredir karın ağrısı yakınmaları nedeniyle termal tedavi almakta iken gelişen ishalde birisi yalancı parazitizm olmak üzere iki farklı helmint ve çok sayıda protozoonun bir arada görüldüğü çoklu parazitizm olgusu sunulmuştur. Hastadan ardışık günlerde üç kez ve tedavi sonrası 1 kez dışkı örneği alındı. Makroskobik ve direkt mikroskobik incelemeler sonrası tüm örnekler formalin-eter çöktürme yöntemi ile hazırlandı. Enterobius vermicularis ve Taenia spp. varlığını araştırmak için selofan-bant yöntemi ile Coccidian parazitler için modifiye Ehrlich-Ziehl-Neelsen (EZN) boyama yöntemleri kullanıldı. Tüm örneklerden en az 4 farklı preparat hazırlandı ve mikroskobik incelemelerde serum fizyolojik, lügol ve trikrom boyama yöntemleri uygulandı. Hastanın getirdiği hareketli segment çini mürekkebi damlatılarak yapılan mikroskobik incelemede Taenia saginata olarak tanımlandı. Dışkının direkt mikroskobik incelemesinde Blastocystis hominis, Endolimax nana kistleri ve Fasciola hepatica yumurtaları görüldü. Formalin-eter çöktürme yönteminde ise Ascaris lumbricoides, Fasciola hepatica yumurtaları, Blastocystis hominis, Endolimax nana ve Entamoeba coli kistleri tanımlanmıştır. Son yıllarda ilimizin artan kentsel gelişim sürecine bağlı olarak, taramalarda oldukça düşük düzeylerde tanımladığımız intestinal parazit varlığının, yetişkin ve immünitesi sağlam bir kişide bu kadar yoğun olarak tanımlanması ilginç bulunmuştur. (Turkiye Parazitol Derg 2013; 37: 157-60)

Anahtar Sözcükler: Bağırsak parazitleri, çoklu parazitizm

Geliş Tarihi: 12.09.2012

Kabul Tarihi: 14.04.2013

\section{ABSTRACT}

It is known that infections caused by intestinal protozoa and helminths affect over 3.5 million people worldwide. In this case report, a patient with complaints of stomach ache for a long time who received thermal treatment is presented. During this thermal treatment, diarrhoea occurred and multiparasitism was diagnosed with two helminths; pseudoparasitism and multiprotozoa, simultaneously. Stool samples were collected from the patient on three consecutive days and one day after the treatment. All of the samples were prepared with formalin-ether sedimentation techniques after macroscopic and direct microscopic investigation. Cellophane-tape method for Enterobius vermicularis and Taenia spp. and Erlich-Ziehl-Neelsen staining method for coccidian parasites were used. At least four preparations were performed for each sample and serum physiologic, lugol' solution and trichrome stain were used for microscopic investigations. The motile segment she brought was investigated microscopically with Indian ink and identified as Taenia saginata. Under direct microscopy, Blastocystis hominis, Endolimax nana and Fasciola hepatica were seen. By formalin-ether sedimentation techniques, Ascaris lumbricoides, Fasciola hepatica, Blastocystis hominis, Endolimax nana and Entamoeba coli were identified. In recent years, intestinal parasitism is rarely seen in our city; therefore, multiparasitism in an adult and immunocompetent patient is interesting.

(Turkiye Parazitol Derg 2013; 37: 157-60)

Key Words: Intestinal parasitism, multiparasitism

Received: 12.09 .2012

Accepted: 14.04.2013

Yazışma Adresi / Address for Correspondence: Dr. Nihal Doğan, Eskişehir Osmangazi Üniversitesi Tıp Fakültesi, Tıbbi Mikrobiyoloji Anabilim Dalı, Parazitoloji Bilim Dalı, Eskişehir, Türkiye Tel: +90222 2392979 E-posta: ndogan@ogu.edu.tr - nihaldogan42@ogu.edu.tr doi:10.5152/tpd.2013.35 


\section{GiRiş}

Çoklu paraziter enfeksiyonlar; gelişmekte olan ülkelerde ve immünitesi baskılanmış hastalarda önemli bir morbidite ve mortalite nedeni olarak bilinmektedir. Bu konuda yapılan çalışmalarında, genellikle tek bir probleme dayalı olması yada sınırlı bir yaş grubunu kapsaması nedeniyle veriler oldukça kısıtlıdır. Kötü hijyen koşulları, düşük sosyoekonomik durum gastrointestinal parazitlerin varlığını ve etkinliğini artırmaktadır (1-5). Birden fazla helminte bağlı intestinal parazit enfeksiyonları sıklıkla tropik bölgelerde rastlanılan bir durumdur ve çoğunda Ascaris lumbricoides olgularına Ancylostoma duedonale ve Trichiurus trichiura birlikteliği eşlik etmektedir. Dünyanın yaklaşık üçte birinin intestinal helmintlerden etkilendiği bilinmektedir (1, 6-8). Ascaris lumbricoides dünyada 1 milyardan fazla kişiyi etkileyen en yaygın helmint enfeksiyonlarındandır (9). Trematod enfeksiyonları da onun kadar yaygın olmakla birlikte belirli coğrafik konum ve beslenme alışkanlıkları nedeniyle bulunma oranları değişkenlik gösterir $(6,10,11)$. Sestodlar; Amerika, Asya ve Afrika kıtasında tarım ve hayvancılığın yaygın olduğu ülkelerde görülen önemli bir halk sağlığı sorunudur (7). CDC raporlarına göre yılda 100 milyardan fazla vaka bildirimi olmaktadır (10). Blastocystis hominis, Endolimax nana ve Entamoeba coli fekal oral bulaşan tüm dünyada en sık görülen protozoon enfeksiyonlarından olup prevalansları \%1-50 arasında değişmektedir (4, 6, 12-14).

\section{OLGU SUNUMU}

Altı aydan beri süregelen gastrointestinal yakınmalar ve son 2 aydır yemeklerden yaklaşık yarım saat sonra aralıklarla tüm karına yayılan kramp tarzında ağı şikayetleri olan 44 yaşında kadın hasta bu şikayetlerle çeşitli defalar farklı hastanelerin farklı polikliniklerine (dahiliye, üroloji, kadın hastalıkları ve doğum) başvurmuş. Buralarda gerekli biyokimyasal tetkikler, batın ultrasonografisi, mide biyopsisi ve kolonoskopi tetkikleri sonrasında, idrar yolları enfeksiyonu ve karaciğerde yağlanma tanısının dışında tüm bulgular normal olarak değerlendirilmiştir. Bulgular doğrultusunda gerekli tedavi protokollerini yerine getiren hasta, şikayetlerinin geçmemesi ve son dönemde giderek artması nedeniyle yakınlarının teşviki ile şikayetlerine çözüm olur düşüncesi ile Ankara/Ayaş'ta bulunan termal/içmeler tesislerine gitmiştir. Beş gün boyunca termal sularından içen hasta da 3 . günden itibaren ishal gelişmiş ve dışkısında farklı büyüklüklerde kurtlar gördüğünü tanımlamıştır. Hasta ishal şikayetleri ve dışkıda gördüğü şüpheli yapılar nedeniyle laboratuvarımıza başvurmuş.

Hastanın hikayesi sorgulandığında ise çocukluğundan beri defalarca başta kıl kurdu olmak üzere tenya ve solucan düşürdüğünü tanımlayan hasta o dönemlerde ara sıra Ayaş kaplıcalarına gittiklerini burada karın ağrılarının geçtiğini söylemektedir. Hastanın 8 ay kadar önce tarım işçisi olarak bir ay tarlada çalıştığı ve çocukluğundan beri çiğ salam sosis zaman zamanda çiğ et tüketme alışkanlığının olduğunu ifade etmektedir. Birden fazla parazitin bir arada görülmesi ve Fasciola yumurtalarının yalancı parazitizm olup olmadığını sorgulanması sırasında, hastanın 2 gün öncesince kurban kestiklerini, koyunun ciğerini doğrarken içinden küçük yassı bir şeylerin çıktığını ancak pişince geçer düşüncesiyle önemsemediğini belirtmiştir.
Hastanın içmelerde düşürdüğü ve laboratuvarımıza getirdiği materyalin mikroskobik incelemesi sonrası Taenia saginata segmenti olduğu tanımlanmıştır. İshal etiyolojisinin araştırılması amacıyla hastadan dışkı örneği alınarak parazitolojik ve mikrobiyolojik tetkikleri yapılmıştır. Parazitolojik incelemede; Fasciola hepatica (Resim 1a) Ascaris lumbricoides yumurtalarının (Resim 1b) yanı sıra, yoğun Endolimax nana ve Blastocystis hominis kistleri (Resim 2) de tanımlanmıştır. Modifiye EZN boyalı preparatlarda coccidian parazit saptanmamış, dışkı kültüründe de patojen mikroorganizma ürememiştir.

Hastaya ilaç tedavisi başlama öncesi 2 gün süre ile kendisinden ve aile bireylerinden dışkı örneği istenmiştir. Ikinci gün yapılan

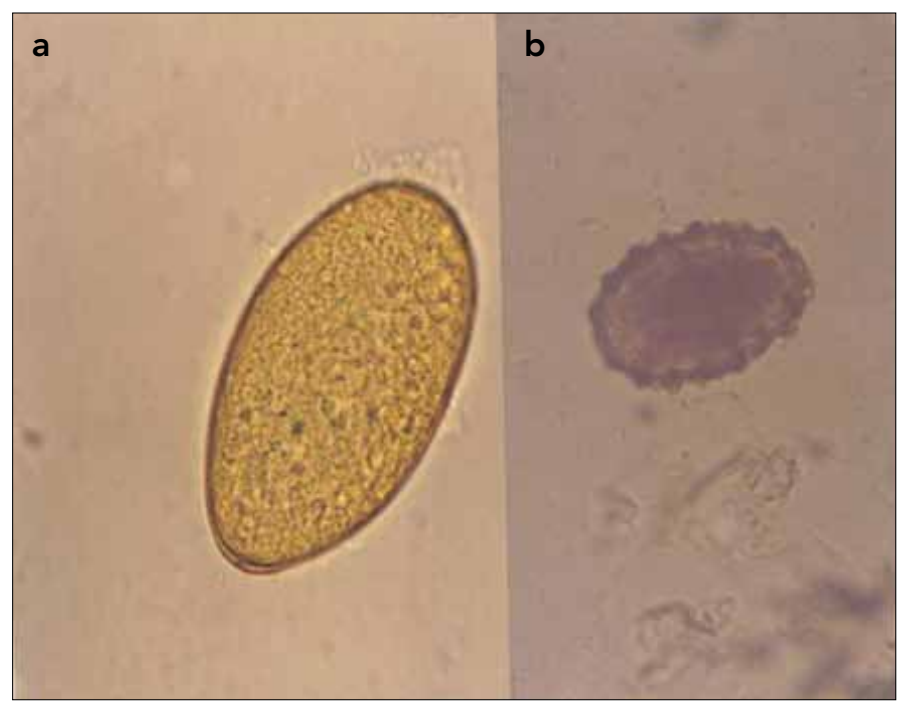

Resim 1. a) Soldaki Fasciola hepatica, b) Sağdaki Ascaris lumbricoides yumurtası

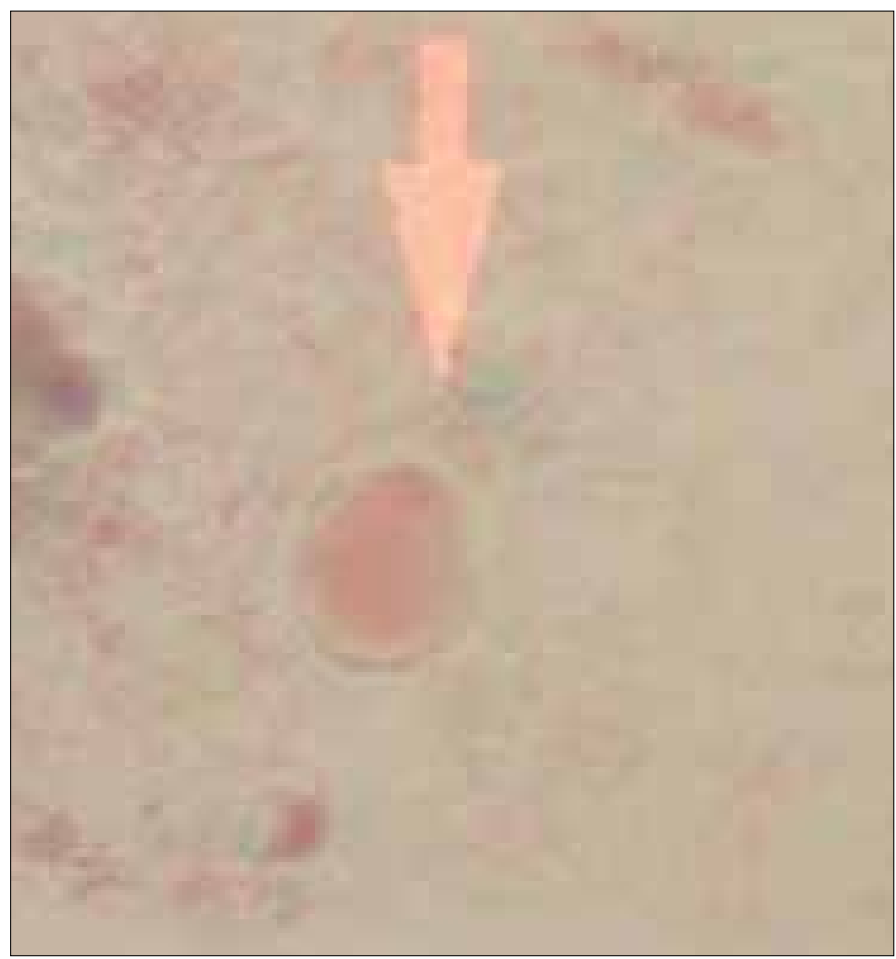

Resim 2. Trichome boyası ile boyanmış Blastocystis hominis kisti 


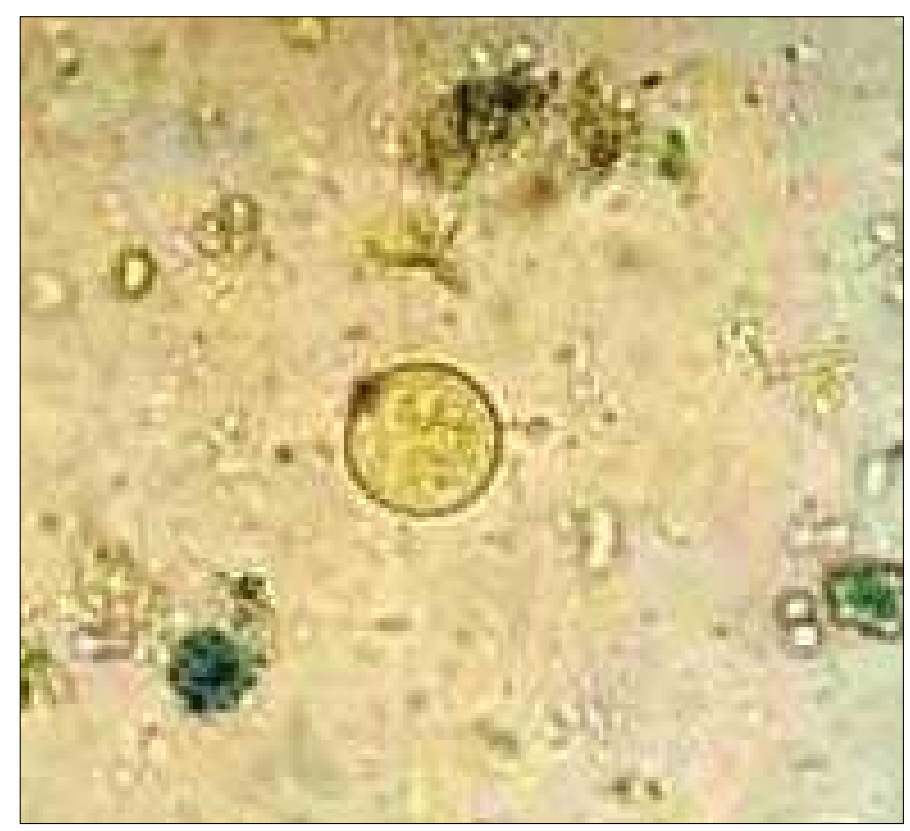

Resim 3. Entamoeba coli kisti

mikroskobik incelemede Ascaris lumbricoides ve az miktarda Facciola hepatica yumurtaları tanımlanırken, Blastocystis hominis ve Endolimax nana kistleri dışında Entamoeba coli kistlerine de (Resim 3) rastlanmıştır. Hastanın eşi örnek vermeyi kabul etmemiş, kızında da yoğun Blastocystis hominis kistleri ile az miktarda Ascaris lumbricoides yumurtaları tanımlanmıştır. Üçüncü gün incelemelerinde Fasciola hepatica ve Ascaris lumbricoides yumurtalarına rastlanmazken, protozoon kistleri yoğun olarak görülmüştür. Illaç tedavisi için enfeksiyon hastalıkları polikliniğine yönlendirilen hastaya 2x100 mg/3 gün mebandazol tedavisi uygulanmış, tedavi bitiminden 2 gün sonra kontrol için laboratuvara çağrıımıştır. Tedavi sonrası alınan örnekte parazit atılımının azaldığı ancak devam etmesi üzerine hastaya bir kür tedavi daha alması önerilmiştir. Helmint tedavisini tamamlanan hastaya protozoonlar için 3x750 mg/7 gün metranidazol tedavisi verilmiştir. Birisi yalancı parazitizm olduğu düşünülen (son yapılan ardışık iki dışkı incelemesinde $F$. hepatica yumurtalarına rastlanmaması ve karaciğer fonksiyon testlerinin normal olması nedeniyle) iki ayrı helmint enfeksiyonunun birlikte görüldüğü hastanın tedavi öncesi yapılan hematolojik ve biyokimyasal test sonuçlarının özellikle de eozinofil ve hemoglobin değerlerinin normal sınırlar içerisinde bulunması ilginç bulunmuştur.

\section{TARTIŞMA}

Parazitolojik yayınlarda gastrointestinal sistemde birden fazla parazitin tanımlanması özellikle tropik bölgelerde, gelişmekte olan ülkelerde çocukluk yaş grubunda ve immünitesi baskılanmış hastalarda yadırganan bir durum değildir (1-5, 8, 11, 15). Hayvanlarla iç içe yaşanan bazı Asya ülkelerinde ve tropik bölgelerde intestinal kanalda bağırsak solucanlarının birkaç türüne aynı olguda rastlamak mümkündür $(1,5,11)$. Çoklu paraziter enfeksiyonlarda birçok potansiyel kombinasyonların olabilirliğinin yanı sıra, özellikle bazı insanların bu duruma yatkınlığının da olabileceği bildirilmektedir $(3,4)$. Olgumuzda çocukluğundan beri sık sık helmint enfeksiyonuna maruz kaldığını, o dönemlerde Ayaş içmeleri- ne gidip burada "kurt düşürdüğünü" söylemiştir. Bu durumun hastanın beslenme alışkanlıklarının yanı sıra, kişisel hijyen ve yatkınlığında rolü olabileceği düşüncesindeyiz. Çiğ tüketilen et ve et ürünleri, toprakla temasın paraziter hastalıkların bulaşımında önemli rolü olduğu bilinmektedir $(1,3,4,8,11,13,14)$.

Hastanın çocukluğundan beri gastrointestinal şikayetlerine yarar sağladığını söylediği Ayaş içmece ve kaplıcaları, zengin mineral yapısı nedeniyle (toplam mineral konsantrasyonu 9348) dünyanın sayılı termal sularından biridir. İki yüzyılı aşkın süredir parazit hastalıkları da dahil, çeşitli metabolik hastalıkların alternatif tedavisinde kullanılmaktadır. İçmece kürü olarak günde dört bardak içilmesi metabolizmayı hızlandırıcı, toksinleri uzaklaştırıcı etkisi ile doğal laksatif özelliği taşıdığı, 3-5 günlük kürler sonrası genel bir zindeliğin yanında mide-bağırsak sistemini rahatlattığı tanımlanmıştır (16). Bu bilgiler doğrultusunda termal sudaki mineraller ve ısınında etkisiyle bağırsaklarındaki hareketlenmeye bağlı parazit atılımının hızlandığı düşünülmektedir.

Birden fazla parazit enfeksiyonlarında iki veya daha fazla antiparaziter ajan eş zamanlı kullanımının ilacın zararlı etkilerini artırabileceği ve çeşitli komplikasyonlara neden olabileceği düşüncesi ile hastaya ilk olarak helmintlere yönelik tedavi daha sonra protozoon tedavisi uygulanmıştır $(6,17)$.

\section{SONUÇ}

Bu olgu, son 5 yılda gerek hastanemiz kayıtlarından gerekse okullarda yaptığımız intestinal parazitolojik incelemelerde bir kaç protozoon parazitin dışında helmint enfeksiyonunun neredeyse hiç tanımlanmadığı ilimizde, kentte bir apartman dairesinde yaşayan, orta gelir düzeyine sahip, immünitesi sağlam bir yetişkinde, bu kadar parazit türünün bir arada bulunmasının yanı sıra; hastanın karın ağrısı şikayetleri ile birçok kliniği dolaşıp birçok ileri tetkiklerin yapılması ancak bir parazitolojik incelemenin akla getirilmemesi nedeniyle farkındalık yaratmak amacıyla sunulmuştur.

\section{Çıkar Çatışması}

Yazarlar herhangi bir çıkar çatışması bildirmemişlerdir.

Hakem değerlendirmesi: Dış bağımsız.

\section{Yazar Katkıları}

Fikir - N.D.; Tasarım - N.D.; Denetleme - N.D.; Kaynaklar - N.D.; Malzemeler - N.D.; Veri toplanması ve/veya işlemesi - N.D., N.U.K.; Analiz ve/veya yorum - N.D.; Literatür taraması - N.D.; Yazıyı yazan - N.D.; Eleştirel İnceleme - N.D.

\section{Conflict of Interest}

No conflict of interest was declared by the authors.

Peer-review: Externally peer-reviewed.

\section{Author Contributions}

Concept - N.D.; Design - N.D.; Supervision - N.D.; Funding N.D.; Materials - N.D.; Data Collection and/or Processing - ND., N.U.K.; Analysis and/or Interpretation - N.D.; Literature Review N.D.; Writing - N.D.; Critical Review - N.D. 


\section{KAYNAKLAR}

1. Brooker S, Clements AC, Bundy DA.Global. Epidemiology, ecology and control of soil-transmitted helminth infections. Adv Parasitol 2006; 62: 221-61.[CrossRef]

2. Rai S, Wadhwa V, Kharbanda P, Uppal B. A case of poly-parasitism involving a trematode and four different nematodes in a migrant from Bihar. Indian J Med Microbiol 2007; 25: 62-3.[CrossRef]

3. Raso G, Luginbühl A, Adjoua CA, Tian-Bi NT, Silué KD, Matthys B, et al. Multiple parasite infections and their relationship to selfreported morbidity in a community of rural Côte d'lvoire. Int J Epidemiol 2004; 33: 1092-102.[CrossRef]

4. Sayasone S, Mak TK, Vanmany M, Rasphone O, Vounatsou P, Utzinger $J$, et al. Helminth and intestinal protozoa infections, multiparasitism and risk factors in Champasack province, Lao Peopless Democratic Republic. PLoS Negl Trop Dis 2011; 5: e1037. [CrossRef]

5. Steinmann P, Utzinger J, Du ZW, Zhou XN. Multiparasitism a neglected reality on global, regional and local scale. Adv Parasitol 2010; 73: 21-50.[CrossRef]

6. WHO. Deworming for health and development. Report of the third global meeting of the partners for parasite control. Geneva 2005; World Health Organisation.

7. Garcia LS. Intestinal helminth: Diagnostic Medical Parasitology 5thedition. Washington DC: American Society for Microbiology pres Washington, DC. 2007.p.263-413.

8. Howard SC, Donnelly CA, Kabatereine NB, Ratard RC, Brooker S. Spatial and intensity-dependent variations in associations between multiple species helminth infections. Acta Trop 2002; 83: 141-9. [CrossRef]
9. Hotez PJ, Ehrenberg JP. Escalating the global fight against neglected tropical diseases through interventions in the Asia Pacific region. Adv Parasitol 2010; 72: 31-53.[CrossRef]

10. CDC Domestic Intestinal Parasite Guidelines. 2012; 1-17.

11. Bhattacharya S, Khurana S, Bhatti HS, Singhi S, Malla N. Polyparasitism: Fasciolopsisbuski, Ascaris lumbricoides and Hookworm coinfection in a child. Tropical Gastroenterology 2010; 31: 126-7.

12. Doğan N, Demirüstü $C$, Aybey $A$. The prevalence of intestinal parasites according to the distribution of the patients' gender and parasite species for five years at the Osmangazi University Medical Faculty. Turkiye Parazitol Derg 2008; 32: 120-5.

13. Pullan R, Broooker S. The health impact of polyparasitism in humans: are we under-estimating the burden of parasitic diseases? Parasitology 2008; 135: 783-94.[CrossRef]

14. Ulukanligil M, Seyrek A. Demographic and socio-economic factors affecting the physical development, haemoglobin and parasitic infection status of school children in Sanliurfa province, Turkey. Public Health 2004; 118: 151-8.[CrossRef]

15. Scott JA, Davidson RN, Moody AH, Bryceson AD. Diagnosing multiple parasitic infections: trypanosomiasis, loiasis and schistosomiasis in a single case. Scand J Infect Dis 1991; 23: 770-80. [CrossRef]

16. Karagülle Z, Doğan MM. Kaplıca Tıbbı ve Türkiye Kaplıca Rehberi, Nobel kitabevi. 2002.s.212.

17. Chiodini PL. Chemotherapy for patients with multiple parasitic infections. Parasitology 2001; 122: 83-9. [CrossRef] 